\title{
Realize Cultural Inheritance in Aesthetics A Probe into the Practice of Film \& in Primary and Secondary Schools
}

\author{
Yunlong Cao* \\ Jiangsu Normal University,Jiangsu 221010,China.
}

\begin{abstract}
As an important content of moral education and aesthetic education, film \& television education in primary and secondary schools has just started, and thus is inevitably facing many problems. The film \& television education in primary and secondary schools should center around the aesthetic characteristics of film \& television education, focus on the cultural elements deeply embedded in the film and television works, and emphasize cultural inheritance in film \& television education, thus improving youngsters' cultural literacy, appreciation ability of film and television works and aesthetic awareness, and promoting their overall development.
\end{abstract}

Keywords:Film and Television Education in Primary and Secondary Schools; Aesthetics; Culture; Educational Path

Like other forms of arts, film and television arts contains rich aesthetic value. In the movie watching experience, the aesthetic subject appreciates the artistic beauty and cultural connotation in film \& TV works through the visual, auditory and other aesthetic forms. Film \& television education in primary and secondary schools should carefully weigh the needs and characteristics of aesthetics of primary and secondary school students, and tap the aesthetic value of film and television resources.

\section{The aesthetic value of film \& television education in primary and secondary schools}

Film \& television education in primary and secondary schools, as a form of aesthetic education, can meet the emotional needs of aesthetic subjects, and improve their aesthetic ability through appreciating film and television works. The aesthetic value of film $\&$ television education in primary and secondary schools is mainly reflected in the following aspects:

First, it enriches the content of aesthetic education. ${ }^{[1]}$ The aesthetic ability is usually built during the appreciation of art works. Art forms such as music, painting, and dance can cultivate and shape the aesthetic perception of young students. Film and television works, as one of the most prevalent art forms in daily life, expand the way in which teenagers elevate their aesthetic tastes with easily accessible forms and richer content.

Second, it develops teenagers' skills of emotional expression. Film and television works are essentially the creative subjects' expression and catharsis of emotions. With the help of film and television works, emotions can be released and sentiment can be cultivated. The aesthetic subject feels and discovers beauty in film and television works. Film \& television education facilitates aesthetic education in that film and television works provide real emotional feelings and arouse resonance.

Copyright (C) 2020 Yunlong Cao

doi: 10.18282/l-e.v9i4.1719

This is an open-access article distributed under the terms of the Creative Commons Attribution Non-Commercial License (http://creativecommons.org/licenses/by-nc/4.0/), which permits unrestricted non-commercial use, distribution, and reproduction in any medium, provided the original work is properly cited.

background music that people don't like has a inhibit function to produce negative emotions. Preferred background music can meet people's needs of the auditory environment and promote the positive emotions. Disliked background music inhibits people from being satisfied in the work environment, and increases negative emotions.

\section{References}

[1]Chen Jianli (1983) BGM-Introduction to Background Music, (Doctoral dissertation)

[2]Feng Ran (2017) Analysis of NetEase Cloud Music's Content Marketing Strategy, Southeast Communication.

[3]Hiroko Fukuda, Kazuyuki Matsumoto, Minoru Yoshida, \& Kenji Kita (2017) Indexing from work BGM based on comments characteristic of music. In Artificial Intelligence Society National Convention Proceedings 31st National Convention (2017) (pp. 2O3OS22b4-2O3OS22b4). The Japanese Society for Artificial Intelligence

[4]Tomio Yoshida. (2007) An old story about how productivity increases with BGM, Journal of the Acoustical Society of Japan, 63 (7), 339-340.

[5]Arikan, M. K., Devrim, M., Oran, Ö., Inan, S., Elhih, M., \& Demiralp, T. (1999). Music effects on event-related potentials of humans on the basis of cultural environment, Neuroscience letters, 268(1), 21-24.

[6]Qin Jian\&Liu Wen (2019) The effect of background music therapy combined with psychological intervention on the anxiety and success rate of patients undergoing ENT endoscopy, Chinese Journal of Health Psychology, (11), 19. 
Third, it stimulates the imagination and creativity. Through appreciating and analyzing film and television works which are usually based on fictional stories, teenagers' intellection can be effectively exercised, which has a positive effect on improving their innovative ability.

Fourth, it promotes the all-round development of teenagers. Film and television works can convey cultural connotations with their unique aesthetic form that combines audio and visual contents and meanwhile alleviate pressure, and play a positive role in promoting the comprehensive development of young people, including mental and physical health.

Therefore, film \& television education in primary and secondary schools should fully tap the aesthetic value of film and television arts, explore aesthetic forms and contents, enhance emotional expression skills, improve imagination and creativity, so as to promote the all-round development of teenagers.

\section{The cultural roadbed of film \& television education in primary and secondary schools}

First, explore the cultural occurrence from the perspective of epistemology. Film \& television education in primary and secondary schools educates students through rich knowledge and theories regarding film and television, and nourishes students through the spiritual culture in film and television works. In terms of practice, such activities as the appreciation of film and television works and creative exchange theme practical activities, students externalize the theoretical knowledge and cultural spirit into actual actions. The enrichment of the content, the expansion of the channels, and the innovation of the carrier of film $\&$ television education in primary and secondary schools will inevitably follow the trend of the times, and realize the cultural transformation with the shift of focus from craft to culture, from being flat to three-dimensional and from heteronomy to selfdiscipline.

Second, explore the cultural characteristics of film \& television education in primary and secondary schools in the new era from the perspective of ontology. "Culture, in the broad sense of ethnography, is a complex whole, which includes knowledge, art, morality, law, customs, and other abilities and habits necessary for individuals as members of society." Art is subordinate to culture, film \& television education is an integral part of art education, and film \& television education in primary and secondary schools should have cultural attributes. The inherent cultural nature of film \& television education in primary and secondary schools is embodied in the cultural orientation of film \& television education in primary and secondary schools in the new era, which aims to improve students' film and television literacy and aesthetic appeal, and presents the content of audio-visual content as educational content and convey the value orientation based on the noble mission of prospering and developing the socialist culture with Chinese characteristics. The cultural characteristics of film \& television education in primary and secondary schools can be summarized as the subjectivity of the goal, the diversity of content, and the loftiness of mission from the perspective of ontology.

Third, explore the cultural practice of film \& television education in primary and secondary schools in the new era from the perspective of practice theory. Film \& television education in primary and secondary schools is inseparable from practical exploration. Enriching the cultural connotations of film \& television education in primary and secondary schools requires enhancing cultural tension. To resist the instrumental and utilitarian evolution requires the injection of cultural power. Improving students' comprehensive quality of film and television arts requires cultural practice. Film \& television education in primary and secondary schools should pay more attention to the improvement of cultural practice quality, and should be carried out in a threedimensional way: cultural infiltration — practice development — creative exchange. Through the integration of traditional culture in film and television works, the enlightenment of revolutionary cultural traditions and the guidance of advanced socialist culture, the students can be equipped with enhanced cultural literacy, enriched spiritual connotation, and improved ideological realm. Through art practice courses, cultural experience on campus, and online and offline exchanges of cutting-edge art and culture, students are provided with opportunities to learn multiculturalism, enhance the perception, appreciation and creativity of beauty, and broaden horizons.

\section{The practice of film \& television education in primary and secondary schools.}

As an important form of quality education for teenagers in primary and secondary schools, film \& television education helps them establish correct values and outlook on life, and cultivate their sense of social mission and historical responsibility. The aesthetic value and cultural connotation of film \& television education have been clarified. In order to realize the enhancement of aesthetic awareness and cultural quality, innovation and optimization of implementation methods for film \& television education, the following aspects need to be carried out:

First, clarify the fundamental task of film \& television education to "lead virtue and cultivate morality". The film \& television education in primary and secondary schools shoulders the lofty mission of cultivating literary and artistic talents. It must adhere to the virtues of cultivating people, and pay equal attention to ethics and talents, so as to develop from the education of cultivating talents to the education of cultivating moral people, break the educational pattern featuring traditional tools and conceptualization, and enhances students' aesthetic sentiment. ${ }^{[2]}$ Film \& television education is rich in forms, free in time and place, and diverse in models. With comprehensive content, film \& television education can be developed from many aspects such as world outlook, outlook on life, values, rule of law and morality. The rich film \& television education resources can be presented to young students vividly, intuitively, multidimensionally. It exerts subtle influence in enhancing the aesthetic sentiment of young students, building up their cultural self-confidence, developing their personality and mindset, so as to truly realize the goal of "lead virtue and cultivate morality".

Second, establish a teacher training system for film \& television education. In view of the current insufficiency of teachers in film \& television education, in the long run, the university film \& television education major should train professional teachers for primary and secondary schools, and in the short term, professional training should immediately commence for part-time teachers. 
At the same time, shortcuts need to be introduced, such as an online training system providing targeted guidance on online teaching and micro-lectures. With the guidance of the Ministry of Education's Guiding Opinions on Strengthening Film \& television education in Primary and Secondary Schools, theoretical and methodological guidance for film \& television education in primary and secondary schools shall be provided with the convergence of experts in drama and film, education, psychology and other disciplines. In addition, exchanges between primary and secondary school film \& television education talents front-line personnel in film and television production is in the need. Through the combination of theory and practice, teachers in primary and secondary schools can be trained with creative ability, theoretical knowledge, appreciation skills and other core qualities necessitated for film $\&$ television education.

Third, integrate the curriculum resources of film \& television education in primary and secondary schools. With reference to the content, teaching methods, and experiences of public art education courses such as music and arts, the teaching content has been designed especially for film \& television education in primary and secondary schools. When choosing film and television works, it is necessary to 1) emphasize the diversity of film and television works, taking into consideration the differences between cities and rural areas, and students of different ages and different knowledge compositions; 2) combine the aesthetic needs and preference of students; 3 ) reflect a certain spirit of the times. For example, a feasible plan is to take the excellent film programs recommended by the Ministry of Education for primary and secondary school students nationwide as the main sources, and invite film and television experts to select films suitable for film and television courses, and pedagogy and psychology experts to advise on teaching methods and plans. Schools and regions where conditions permit can also invite front-line practitioners to guide teachers and students on shooting, thus better integrating theory and practice and informing teachers with practical teaching experience. By doing so, teachers and students' level of art appreciation, art criticism, art creation, art innovation, and even art comparison and art research can be elevated in the process of film and television teaching.

\section{Conclusion}

To sum up, film \& television education in primary and secondary schools shall gradually enhance the aesthetic cognition of teenagers, taking cultural inheritance as its core. The only way to get rid of the predicament and innovate primary and secondary school film \& television education is to fully understand its aesthetic characteristics, and sort out its cultural roots and cultural inheritance path. Faced with the current problems, we should identify fundamental tasks, pool resources, design reasonable and standardized curricula, and enrich teaching practices. The purpose is to promote the all-round development of students and pass on the spirit of Chinese culture. This will be an important measure to explore the methods of film \& television education in primary and secondary schools and answer to the higher calls of the times.

\section{References}

[1]Gong Jinping. Exploration of the Significance and Implementation Path of "Leading Morality" in the Film and Television Curriculum of Primary and Secondary Schools[J]. Shanghai Curriculum Teaching Research, 2018, 000(001):11-14,76.

[2]Zhang Houping. The status quo and development path of film \& television education in Henan primary and secondary schools[J]. Journal of Henan Institute of Education: Philosophy and Social Sciences Edition, 2019(6):38-40. 